\title{
Emitter Clogging and Hydraulic Performance of Drip System under Different Water Qualities and Placement Techniques
}

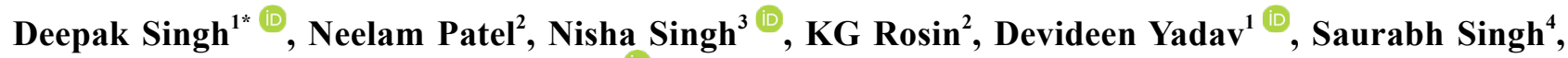 \\ Anand Kumar Gupta ${ }^{1}$, Anita Kumawat ${ }^{5}$, Vinod Kumar Sharma $^{2}$, Manoj Kumar \\ ${ }^{1}$ ICAR-Indian Institute of Soil and Water Conservation, Dehradun, Uttarakhand, India \\ ${ }^{2}$ ICAR-Indian Agricultural Research Institute, New Delhi, India \\ ${ }^{3}$ Hemvati Nandan Bahuguna Garhwal University (A Central University), Srinagar (Garhwal), Uttarakhand, India \\ ${ }^{4}$ Rani Lakshmi Bai Central Agricultural University, Jhansi, Uttar Pradesh, India \\ ${ }^{5}$ ICAR-Indian Institute of Soil and Water Conservation, Research Center Kota, Rajasthan, India \\ ${ }^{6}$ ICAR-Indian Institute of Soil and Water Conservation, Research Center Chandigarh, India \\ E-mail:dpk905@gmail.com; ydeviari@gmail.com
}

Received: 16 June 2021; Revised: 15 September 2021; Accepted: 18 October 2021

\begin{abstract}
The present study was conducted at the Indian Agricultural Research Institute, New Delhi, India, to evaluate the effect of sand-disc filters, pressure compensating (bioline) and non-pressure compensating (inline) emitters, and surface and subsurface placement of laterals on emitter clogging using wastewater and groundwater for irrigation. Results of this study revealed that besides water quality, the type of emitter, placement of laterals, and emitter position on laterals affected emitter's clogging. The major cause of clogging was associated with the precipitated substance accumulated at the emitter inlet concurrently close the micro-pore channels of the emitter, consequently reduce the emitter discharge. The major substances that took part in the clogging of emitter were EC, $\mathrm{pH}, \mathrm{HCO}_{3}$, Turbidity, total solid, Escherichia coli $\left(E\right.$. coli), and total coliform. It was observed that these substances $\left(\mathrm{HCO}_{3}\right.$, Turbidity, total solid, E. coli, and total coliform) of groundwater and wastewater were categorized with a medium risk of clogging except for magnesium (low risk of clogging). Pressure compensating drip emitter showed better performance against clogging as compared to non-pressure compensating drip emitter. Sub-surface placement of drip emitter was more prone to clogging under both wastewater and groundwater. It was observed a significant $(\mathrm{p} \leq 0.05)$ effect of lateral placement, emitter types, and the interaction between these factors on emitter's clogging under both types of water. Emitter flow rate decreased with the increasing time of operation of the drip systems at normal operating pressure, because of clogging of emitters. By flushing operation, it was observed a 3 to $5 \%$ higher flow rate in inline drip emitter than bioline (1-2\%). The $\mathrm{R}^{2}$ value, which precisely describes the head-discharge relationship, was high (0.99) in most of the bioline treatments. This study also observed and recommended that pressure compensating emitter would be the most appropriate technique to reduce the clogging while using wastewater for irrigation. Flushing effectively controlled the emitter's clogging thus improved the emitter's water discharge rate.
\end{abstract}

Keywords: wastewater, surface and subsurface placement, pressure compensating and non-pressure compensating emitter, emitters clogging

Copyright (C2021 Deepak Singh, et al

DOI: https://doi.org/10.37256/fse.222021993

This is an open-access article distributed under a CC BY license

(Creative Commons Attribution 4.0 International License)

https://creativecommons.org/licenses/by/4.0/ 


\section{Introduction}

Water demand is increasing because of the fast population growth, improvement in living standards, along with growth in industry and urbanization. The freshwater for irrigation use is declining rapidly, while the demand for the same is increasing continuously [1-2]. There is a significant challenge to produce more food for the growing population from limited water. Therefore, the efficient use of irrigation water is of paramount importance for sustainable agricultural development [3-4]. Because of the increasing migration of the rural population towards urban areas, the flow of household wastewater into the water bodies has increased, which has led to various environmental problems [5]. Although wastewater contains various pollutants, it is also rich in nutrients that benefit plant growth [6]. Hence, an efficient way to use wastewater from an environmental point of view is to use it in agriculture. In many parts of the world, including India, wastewater is used for irrigation in various land-use systems such as pastures, forests, parks, and golf courses [7] and vegetable cultivation [8]. A drip irrigation system can reduce the risks associated with wastewater use, such as plant toxicity, water pollution, and direct contact with irrigation devices and consumer products [9]. However, filter clogging and emissions are the major problems seen under drip irrigation systems when using wastewater [10]. The dripper, the filtration process, the morphological and chemical composition of the suspended particles, etc. directly affect the emitter blockage [11]. The clogging of emitters and filters mainly comprises three types (1) physical clogging: caused by the deposition of sand, silt, and clay particles together with debris [12], (2) chemical clogging: because of the interaction of dissolved solids with each other to form calcium carbonate deposits [13] and (3) biological clogging: because of algae, iron mud, and sulfur slurries in the water [14-15]. Tertiary treatment and chlorination are two effective methods to reduce the clogging of drip emitters but have been costly [16]. The filtration unit is the heart of the drip irrigation system because it removes impurities from water, which helps to avoid emitter clogging [10]. But most of the time, the filter gets clogged due to low-quality water [17]. The most commonly used filtration systems in India are sand media filters, disc filters, and screen filters (Tripathi et al., 2014) [7]. Sand media filter which prevents the passing of suspended solids larger than the filter pour is useful for water having a high suspended solids content [18-19]. A disc filter is used for water having organic materials and fitted after the sand media filter, while a screen filter is lightweight, simple, and economic, but it is restrictedly used only for quality groundwater and settled wastewater [20]. The combined use of the sand-disk filter is a very effective strategy to improve the removal efficiency of the filtration system [21].

Along with filtration systems, emitter design is also a key factor to reduce the clogging of emitters. Various types of anti-clogging emitter designs such as tube emitter system with laminar flow [22-23], labyrinth type emitter [21], and dripper having high flow [24] have also been developed. However, flushing the laterals in the regular interval has also been effective to reduce the clogging of emitters. Flushing the laterals even once a month had a significant impact against emitter clogging compared to no flushing [25]. Wastewater application through the drip system results in higher installation and operation costs owing to the clogging of emitters and filters [26]. Because of the serious scarcity of fresh water for irrigation, the wastewater can be used efficiently for irrigation through the drip system, but it is necessary to overcome the problems of clogging of emitters and filters [27]. For this purpose, performing different emitters can be evaluated; simultaneously, some adjustments in the installation of the filters can be done. Research on drip irrigation always focused to reduce clogging problems of emitters and filters using wastewater for irrigation through some modifications in the operation of emitters, however, these studies have mostly been conducted in laboratories [28-29] while in the open field case, clogging of emitters and filters appears to be a more serious problem [30-31]. The present study evaluated the effect of different emitters, sand disc filters, and placement techniques of drip laterals on clogging of emitters when wastewater and groundwater are used for irrigation through a drip system.

\section{Materials and methods}

\subsection{Experimental site \& climatic conditions}

The study was conducted at the Precision Farming Development Centre of Indian Agricultural Research Institute (IARI), New Delhi, India. The experimental field is located at $28^{\circ} 38^{\prime} 11^{\prime \prime} \mathrm{N}, 77^{\circ} 09^{\prime} 54^{\prime \prime} \mathrm{E}$. The location had a subtropical semiarid with hot dry summer and cold winter. The mean annual temperature is $24{ }^{\circ} \mathrm{C}$, which varied from $45^{\circ} \mathrm{C}$ in June 
and $7{ }^{\circ} \mathrm{C}$ in January. The mean annual rainfall based on 100 years record (1901-2000) is $790 \mathrm{~mm}$.

\subsection{Experimental setup}

A plot measuring $51 \mathrm{~m} \times 30 \mathrm{~m}$ was selected for the experiments. The plot was divided into two units of $25 \mathrm{~m} \times$ $30 \mathrm{~m}$ each with a $1 \mathrm{~m}$ buffer strip. Each plot comprised four treatments, which were repeated thrice. Treatments were designed in a factorial randomized block design as shown in Table 1. Lateral lines were spaced at $60 \mathrm{~cm}$ apart, which was laid on the plant row, and emitters spacing was $40 \mathrm{~cm}$ (plant to plant spacing was also $30 \mathrm{~cm}$ ). The total number of drippers in each lateral line was 75 . The detailed descriptions of the drip system and experimental site are mentioned by [9].

Table 1. Detail of the experimental treatments

\begin{tabular}{cc}
\hline Treatments & Detail \\
\hline T1 & Groundwater application in inline surface drip \\
T2 & Groundwater application using inline subsurface drip \\
T3 & Groundwater application using bio line surface drip \\
T4 & Groundwater application using bio line subsurface drip \\
T5 & Wastewater application using inline surface drip \\
T6 & Wastewater application using inline subsurface drip \\
T7 & Wastewater application using bio line surface drip \\
T8 & Wastewater application using bio line subsurface drip \\
\hline
\end{tabular}

Note: Inline: non-pressure compensating emitter, Bioline: pressure compensating emitter Surface drip: lateral placement at the ground surface, subsurface drip: lateral placement inside the ground $(30 \mathrm{~cm}$ below the ground).

\subsection{Operational procedure}

Wastewater was collected from a sewage line that runs approximately 500 meters from the experimental field. Two wastewater collection tanks were established, one of them near the sewage line to hold the wastewater for one day to remove floating material and allow suspended particles to settle. The second tank was established near the experimental site to collect the deposited wastewater from the first tank to improve the quality of wastewater by reducing suspended particles. Wastewater from the second tank was applied to the experimental plots through different filtration systems (sand media filter and disc filter) to prevent the clogging of the drip system and to reduce the microbial population [21].

The performance of the system was evaluated at an operating pressure of $1 \mathrm{~kg} \times \mathrm{cm}^{-2}$ to provide sufficient irrigation water for the soil type (sandy-loam) to avoid ponding near the root zone of the crop [9]. A digital pressure gauge was used to measure the pressure at the laterals and at the emitters to maintain an accurate pressure of the system. A catchcan method was applied to measure the required quantity of water to check the flow rate of the emitters. Whereas in the case of subsurface drip placement, the flow rate of emitters was analyzed using the method given by [32]. The flushing of the system after the experiment by dispersing groundwater and wastewater by operating the system at $2 \mathrm{~kg} \times \mathrm{cm}^{-2}$ for 10 minutes. Immediately after flushing, the emitter flow rate was measured.

\subsection{Evaluation of filter performance}

The performance of the filter was evaluated by estimating the removal efficiency of the filtration systems using the following equation. 


$$
R E=\left(N_{0}-N\right) / N_{0}
$$

where $N_{0}$ is a measured quality parameter at the filter inlet; and $N$ is the same parameter at the filter outlet.

\subsection{Assessment of emitter performance}

\subsubsection{Head-discharge relationship of drippers}

Head-discharge relationship of drippers can be characterized by drawing a relationship between dripper flow rate Vs applied pressure head using curve fitted equation as follows:

$$
q=C H^{x}
$$

where, $q$ is a dripper flow rate $\left(\mathrm{m}^{3} \times \mathrm{s}^{-1}\right), H$ is the pressure head $(\mathrm{m}), x$ represents dipper exponent characteristics and $C$ is emitter coefficient.

\subsubsection{Coefficient of variation $\left(C V_{q}\right)$}

The $C V_{q}$ in the emitter flow rate was estimated using the Eq. (3) [13].

$$
C V q=S D / q \times 100
$$

where $S D$ is the standard deviation of dripper discharge $\left(\mathrm{L} \times \mathrm{h}^{-1}\right)$ and $q$ is the mean discharge of emitters in the same lateral $\left(\mathrm{L} \times \mathrm{h}^{-1}\right)$.

\subsubsection{Discharge variation}

The dripper discharge variation $(R)$ from the percentage of the initial discharge was estimated using the following equation:

$$
R=\left(\frac{q}{q_{\text {ini }}}\right) \times 100
$$

where $q$ is the mean emitter discharge and $q_{i n i}$ is the initial discharge of the dripper. During, the measurement of the discharge from the dripper, and the operating pressure should be the same for both conditions.

\subsubsection{Distribution uniformity $(D U)$}

DU of the drip system was calculated by adopting the procedure of [33] as mentioned below:

$$
D U=\frac{q_{25}}{q} \times 100
$$

where $q$ is the mean flow rate of all the dripper tested $\left(\mathrm{L} \times \mathrm{h}^{-1}\right)$ and $q_{25}$ is the mean flow rate of the dripper (the lowest discharge of the $25 \%$ drippers $)\left(\mathrm{L} \times \mathrm{h}^{-1}\right)$.

\subsubsection{Observation of the emitter}

The visual analysis of clogging of drip emitters at the beginning and end of the experiment was also performed. The emitters were cut and examined externally with the help of a photograph taken by the microscope. 


\subsection{Statistical analysis}

A factorial randomized block design was applied in the experimental field with eight treatments which were three factors at two levels i.e. factors: water types, placement of drip laterals, and type of drip laterals. Analysis of variance (ANOVA) analyzed the data using full factorial procedures by SPSS (16) software. The treatment's mean was compared by the Tukey test at a p-value of 0.05 or less.

\section{Results and discussion}

\subsection{Irrigation water quality}

Table 2. Physio-chemical and biological analyzes for groundwater and wastewater, with the classification for risk of clogging

\begin{tabular}{|c|c|c|c|}
\hline \multirow{2}{*}{ Parameters } & \multirow{2}{*}{ Unit } & Wastewater & Groundwater \\
\hline & & Mean $\pm \mathrm{SD}$ & Mean $\pm \mathrm{SD}$ \\
\hline $\mathrm{pH}$ & - & $6.89 \pm 0.16^{* a}$ & $7.4 \pm 0.19 * a$ \\
\hline $\mathrm{EC}$ & $\mathrm{dS} \times \mathrm{m}^{-1}$ & $1.70 \pm 0.18 * * \mathrm{a}$ & $2.17 \pm 0.26^{* * a}$ \\
\hline $\mathrm{HCO}_{3}$ & $\mathrm{mg} \times \mathrm{L}^{-1}$ & $410.5 \pm 32.82 * * \mathrm{a}$ & $369.2 \pm 43.13 * a$ \\
\hline Turbidity & NTU & $44.0 \pm 10.12 \#$ & $1.50 \pm 0.13 \#$ \\
\hline $\mathrm{Ca}$ & $\mathrm{mg} \times \mathrm{L}^{-1}$ & $95.23 \pm 23.80^{* *} \mathrm{ab}$ & $44.58 \pm 6.24 * \mathrm{ab}$ \\
\hline $\mathrm{Mg}$ & $\mathrm{mg} \times \mathrm{L}^{-1}$ & $32.59 \pm 5.12 * \mathrm{ac}$ & $35.28 \pm 4.35^{*} \mathrm{ac}$ \\
\hline Total solids & $\mathrm{mg} \times \mathrm{L}^{-1}$ & $852.21 \pm 117.83 * * b c$ & $939.28 \pm 154.78 * * b c$ \\
\hline E.coli & $\mathrm{CFU} \times \mathrm{mL}^{-1}$ & $347124 \pm 28457 * * * a b$ & nd \\
\hline Total coliform & $\mathrm{MPN} \times \mathrm{mL}^{-1}$ & $135484 \pm 33871^{* * * a b}$ & nd \\
\hline $\mathrm{BOD}_{5}$ & $\mathrm{mg} \times \mathrm{L}^{-1}$ & $126 \pm 30.24 \#$ & $0.725 \pm 0.10 \#$ \\
\hline
\end{tabular}

nd: not detected, *low risk of clogging, **medium risk of clogging, ***high risk of clogging, \#not available. Classification according to a-Ayers and Wistcot, 1991; b-Capra and Scicolone, 1998; c-Nakayama et al., 2007

The average values of these main clogging parameters and categorization of their respective risk of clogging for irrigation waters are presented in Table 2. Electrical conductivity (EC) and $\mathrm{pH}$ values for wastewater were lower than the groundwater. Variation in the EC values for groundwater was from 1.92 to $2.43 \mathrm{dS} \times \mathrm{m}^{-1}$ with an average of $2.17 \mathrm{dS}$ $\times \mathrm{m}^{-1}$ but for wastewater, it was in the range of 1.48 to $1.88 \mathrm{dS} \times \mathrm{m}^{-1}$ with a mean of $1.70 \mathrm{dS} \times \mathrm{m}^{-1}$. Whereas, $\mathrm{pH}$ values varied from 7.21 to 7.6 for groundwater with an average of 7.40 higher than wastewater (mean value 6.89 ). The average value of bicarbonate for wastewater and groundwater was $410.5 \mathrm{mg} \times \mathrm{L}^{-1}$ and $369.2 \mathrm{mg} \times \mathrm{L}^{-1}$ respectively. The calcium value of wastewater and groundwater was recorded at 95.23 and $44.58 \mathrm{mg} \times \mathrm{L}^{-1}$ respectively. E. Coli was found in order of $10^{-6} \mathrm{CFU} \times \mathrm{ml}^{-1}$ and Total coliform also having a similar order of magnitude in wastewater. $\mathrm{BOD}_{5}$ value in wastewater was observed $126 \mathrm{mg} \times \mathrm{L}^{-1}$. The main emitter clogging agents present in groundwater and wastewater were categorized based on the category suggested by [34] and verified through physicochemical and biological analyses. As the $\mathrm{pH}$ value of wastewater indicating slightly acidic than groundwater. Both the water had the low risk of clogging category which showed that this parameter may not directly influence the clogging but helps in biological growth and chemical reaction [7]. The EC value in wastewater was lower than the groundwater likely due to less salt content in wastewater indicating a lower risk of clogging than groundwater [4]. Bicarbonate and turbidity of wastewater were much higher than the groundwater, maybe due to the presence of foreign particles, and carbonate gets converted into bicarbonate 
[20]. This was indicated that the presence of a high level of bicarbonate and turbidity in wastewater was more prone to clogging i.e. medium to high-risk clogging category (Table 2). The magnesium content in wastewater was lower than in groundwater. The biological parameters such as Escherichia coli (E. coli) and Total coliforms showed a high risk of clogging in wastewater, whereas in groundwater they were not detected. Almost all physio-chemical parameters of groundwater and wastewater were categorized with a medium risk of clogging except for $\mathrm{pH}$ and magnesium (low risk of clogging). Based on the above water quality attributes, the application of wastewater was more prone to clogging than the groundwater.

\subsection{Filter performance}

The removal efficiency of the sand-disc filter for groundwater and wastewater during the experiment is shown in Table 3. The higher removal efficiency was observed for turbidity $(34.74 \pm 5.56 \%)$ and the total solid $(21.83 \pm 3.27 \%)$ in wastewater application. The overall average removal efficiency was observed to be $12.41 \pm 3.10 \%$ and $7.31 \pm 1.31 \%$ for wastewater and groundwater, respectively. It was observed that the maximum removal efficiency of Escherichia coli $(42.97 \pm 10.31 \%)$ and total coliform $(48.79 \pm 11.23 \%)$ in wastewater. The removal efficiency of biological oxygen demand was $5.67 \pm 1.53 \%$ for wastewater and $5.51 \pm 1.04 \%$ for groundwater. Some reduction in organic matter contaminant through the filtration was also observed. The sand-disc filter lowered the EC at a higher rate in wastewater than groundwater, while removal efficiency of $\mathrm{pH}$ was less in wastewater than groundwater. By utilizing the filtration system, the clogging risk was reduced. The filtration system was lowered the $\mathrm{EC}$ and $\mathrm{pH}$ by 3 to $6 \%$ whereas, bicarbonate and turbidity were lowered by 18 to $34 \%$ in wastewater. The removal efficiency of these parameters was well within the results reported by other researchers $[8,17]$. These total solid and turbidity removal efficiencies help in lowering the physical clogging risks in drip emitters [10]. The removal efficiency of $84.60 \pm 1.88 \%$ for E. coli and 95.24 $\pm 3.39 \%$ for total coliform with sand-disc filters using wastewater [7]. A reduction in organic materials using sand-disc filters, reducing the clogging level in the drip system was reported by [15]. Other research findings also support the present results [35]. Hence, it was recorded that the combined use of sand-disc filters reduces the risk of clogging in drip irrigation systems.

Table 3. The mean and standard deviation of the removal efficiency of both the water parameters obtained by the combined sand-disc filtration system

\begin{tabular}{ccc}
\hline & Wastewater & Groundwater \\
\cline { 2 - 3 } Parameters & Mean $\pm \mathrm{SD}$ & Mean $\pm \mathrm{SD}$ \\
\hline $\mathrm{pH}$ & $6.31 \pm 0.95$ & $6.47 \pm 0.90$ \\
$\mathrm{EC}$ & $3.59 \pm 0.47$ & $3.46 \pm 0.42$ \\
$\mathrm{HCO}_{3}$ & $18.58 \pm 2.60$ & $19.14 \pm 3.04$ \\
Turbidity & $34.74 \pm 5.56$ & $5.74 \pm 0.98$ \\
$\mathrm{Ca}$ & $12.19 \pm 02.07$ & $10.23 \pm 1.64$ \\
$\mathrm{Mg}$ & $12.41 \pm 3.10$ & $7.31 \pm 1.31$ \\
Total solids & $21.83 \pm 3.27$ & $18.12 \pm 3.80$ \\
E.coli & $42.97 \pm 10.31$ & nd \\
Total coliform & $48.79 \pm 11.23$ & nd \\
BOD & $5.67 \pm 1.53$ & $5.51 \pm 1.04$ \\
\hline
\end{tabular}

nd: not detected 


\subsection{Assessment of emitter performance}

\subsubsection{Head-discharge relationship of emitters}

Table 4. Head-discharge relationships under different experimental treatments

\begin{tabular}{|c|c|c|c|c|}
\hline Treatment & Stage & Coefficient & Exponent & $\mathrm{R}^{2}$ \\
\hline \multirow[t]{3}{*}{$\mathrm{T} 1$} & B & 3.585 & 0.455 & 0.99 \\
\hline & BSY & 3.524 & 0.455 & 0.99 \\
\hline & ASY & 3.498 & 0.451 & 0.99 \\
\hline \multirow[t]{3}{*}{$\mathrm{T} 2$} & B & 3.565 & 0.443 & 0.99 \\
\hline & BSY & 3.534 & 0.442 & 0.99 \\
\hline & ASY & 3.458 & 0.441 & 0.99 \\
\hline \multirow[t]{3}{*}{$\mathrm{T} 3$} & B & 3.595 & 0.499 & 0.99 \\
\hline & BSY & 3.544 & 0.496 & 0.99 \\
\hline & ASY & 3.488 & 0.494 & 0.99 \\
\hline \multirow[t]{3}{*}{$\mathrm{T} 4$} & B & 3.575 & 0.498 & 0.99 \\
\hline & BSY & 3.514 & 0.495 & 0.99 \\
\hline & ASY & 3.508 & 0.493 & 0.99 \\
\hline \multirow[t]{3}{*}{ T5 } & B & 3.455 & 0.442 & 0.99 \\
\hline & BSY & 3.424 & 0.445 & 0.99 \\
\hline & ASY & 3.418 & 0.441 & 0.98 \\
\hline \multirow[t]{3}{*}{ T6 } & B & 3.445 & 0.442 & 0.99 \\
\hline & BSY & 3.423 & 0.439 & 0.99 \\
\hline & ASY & 3.417 & 0.436 & 0.98 \\
\hline \multirow[t]{3}{*}{$\mathrm{T} 7$} & B & 3.585 & 0.499 & 0.99 \\
\hline & BSY & 3.543 & 0.494 & 0.99 \\
\hline & ASY & 3.476 & 0.492 & 0.99 \\
\hline \multirow[t]{3}{*}{$\mathrm{T} 8$} & B & 3.554 & 0.498 & 0.99 \\
\hline & BSY & 3.497 & 0.494 & 0.99 \\
\hline & ASY & 3.487 & 0.491 & 0.99 \\
\hline
\end{tabular}

B-beginning of the experiment, BSY-beginning of the second year of the experiment, ASY-after completion of the second year of the experiment

Head-discharge relationships were derived at the beginning of the experiment, at the beginning of the second year of the experiment, and after completion of the experiment (second year) for all the treatments. It was found that the small values of emitter coefficients with inline drip emitters as compared to bioline, which showed that inline drip emitters are more vulnerable to clogging. The subsurface emitters showed more susceptibility to clogging as compared to surface drip laterals in both wastewater and groundwater. The emitter coefficient was found lower in all the treatments at the end of the second year of the experiment (Table 4). At normal operating pressure, the exponent for inline emitters and subsurface drip laterals was lower than the bioline emitter and surface drip laterals. Overall, bioline emitter along with surface placement of laterals reduced clogging of the emitter. The flow rate of emitters is controlled by the 
hydraulic pressure at the emitter and the flow path dimension of the emitter. As for manufacture design, the exponent $\mathrm{x}$ is 0.50 when the flow through the emitter is considered as fully turbulent with a manufacture's design exponent of 0.5 [36-37]. In the present study, two types of emitters were used as pressure compensating and non-pressure compensating. The flow rate variability was negligible at a beginning of the experiment, which means there was no turbulence effect on the flow rate on both the emitters. At the end of the second year of the experiment, we found small values of emitter coefficients with inline drip emitters as compared to bioline, which showed that inline drip emitters are more vulnerable to clogging. Furthermore, subsurface placed emitters also showed more susceptibility to clogging as compared to surface drip laterals in both waste and groundwater. Some researchers also observed a more clogging risk of nonpressure compensating drip emitters as compared to pressure compensating using wastewater $[10,15]$. The bioline has a pressure compensating mechanism which helped the lateral to run without clogging regarding varying heads. However, such a mechanism was not present in the inline drip lateral [6]. The $\mathrm{R}^{2}$ value which precisely describes the head-discharge relationship was high (0.99) in most of the bioline treatments. Overall, bioline emitter along with surface placement of laterals reduced clogging of the emitter.

\subsubsection{Emitter flow rate and emitter location}

Table 5. Significant level (p-value) of the statistical model and each factor and interaction for flow rate variability and its variation during the experiment

\begin{tabular}{|c|c|c|c|}
\hline Factor and Interaction & $\mathrm{B}$ & BSY & ASY \\
\hline Model & ns & $* *$ & $* * *$ \\
\hline Water & ns & $* * *$ & $* * *$ \\
\hline Depth & ns & $*$ & $* *$ \\
\hline System & ns & $* *$ & $* * *$ \\
\hline Water $\times$ Depth & ns & $*$ & $* * *$ \\
\hline Water $\times$ System & ns & $* * *$ & $* * *$ \\
\hline Depth $\times$ System & ns & ns & $* *$ \\
\hline Water $\times$ Depth $\times$ System & ns & $* * *$ & $* * *$ \\
\hline
\end{tabular}

ns: non-significant, $* \mathrm{P}<0.05, * * \mathrm{P}<0.01, * * * \mathrm{P}<0.001$

B-beginning of the experiment, BSY-beginning of the second year of the experiment, ASY-after completion of the second year of the experiment

The variation in emitter flow rate was recorded with taking care of the pressure variation, so that flow rate reduction can only be explained by clogging of emitters. The average flow rate variations during the study period under different emitters for both types of water are presented in Figure 1a, $1 \mathrm{~b}$ and $1 \mathrm{c}$. At the beginning of the experiment, flow rate variation was equal to the initial flow rate given by the manufacturer (Figure 1a). But after the first year, the flow rate was reduced in all the treatments (Figure 1b). It was observed that the maximum reduction in wastewater flow rate with inline emitter and subsurface placement of laterals while the minimum flow rate of groundwater was recorded in bioline and surface placement of drip lateral. The interaction effect of different parameters on the flow rate of the emitter is presented in Table 5. A significant effect of lateral placement, emitter types, and their interaction was observed on emitters clogging in both types of water. Dripper flow rate variation study was done by maintaining constant pressure to the drip systems, so that any changes in the flow rate can be explained only by the clogging of the dripper. The results of the statistical analysis showed that at the beginning of the experiment there was hardly any significant difference was found among the depth, placement, and type of lateral are likely due to new drippers has a negligible chance of clogging $[7,17]$. This result can also be validated by DU which had the value almost near to manufacturer-designed values at the beginning of the experiment (Figure 2). After the end of the experimental period, a highly significant difference was observed among the interaction effects of the depth, placement, and type of lateral. This is due to the continuous use 
of wastewater which was having medium to high risk of clogging potential (Table 2). Moreover, in the first year of the experiment, the $\mathrm{CV}$ was less than the recommended limit (10.0\%), which is rated good as per [38]. But in the second year, CV was higher than the prescribed limit [38] in the case of using wastewater with inline laterals, indicating that inline is more prone to clogging. Results also revealed that the bioline drip laterals showed excellent performance as per the prescribed limit in both the years over inline drip laterals.
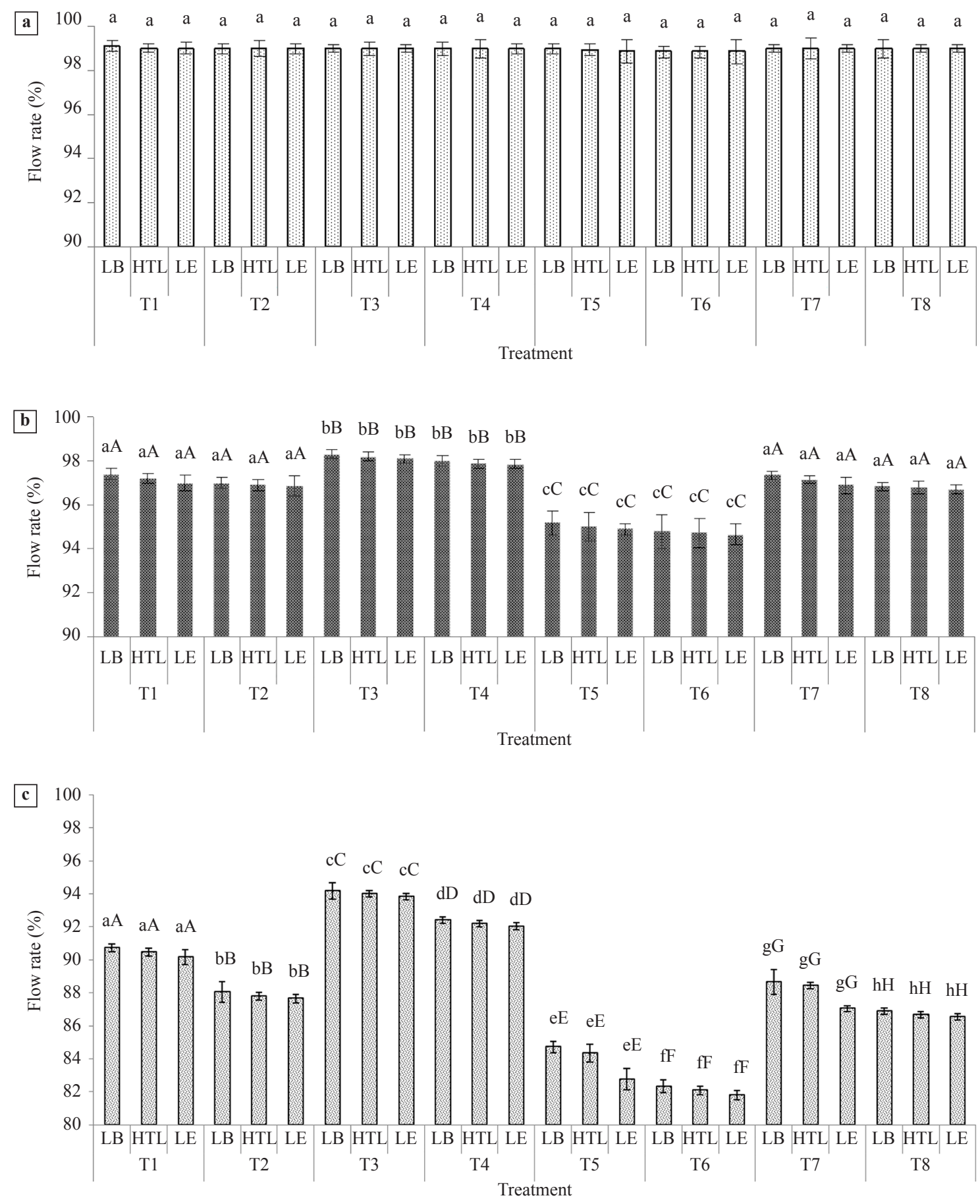

Figure 1. Average flow rate and standard deviation of the emitters and their location under different treatments during the study period Different small letters mean significant differences at $\mathrm{P}<0.05$ among the emitter location, while different capital letters mean significant differences at $\mathrm{P}<0.05$ among the treatments. LB-emitter at the lateral beginning, HTL-emitter at half of the total length, and LE-emitter at the lateral end. 


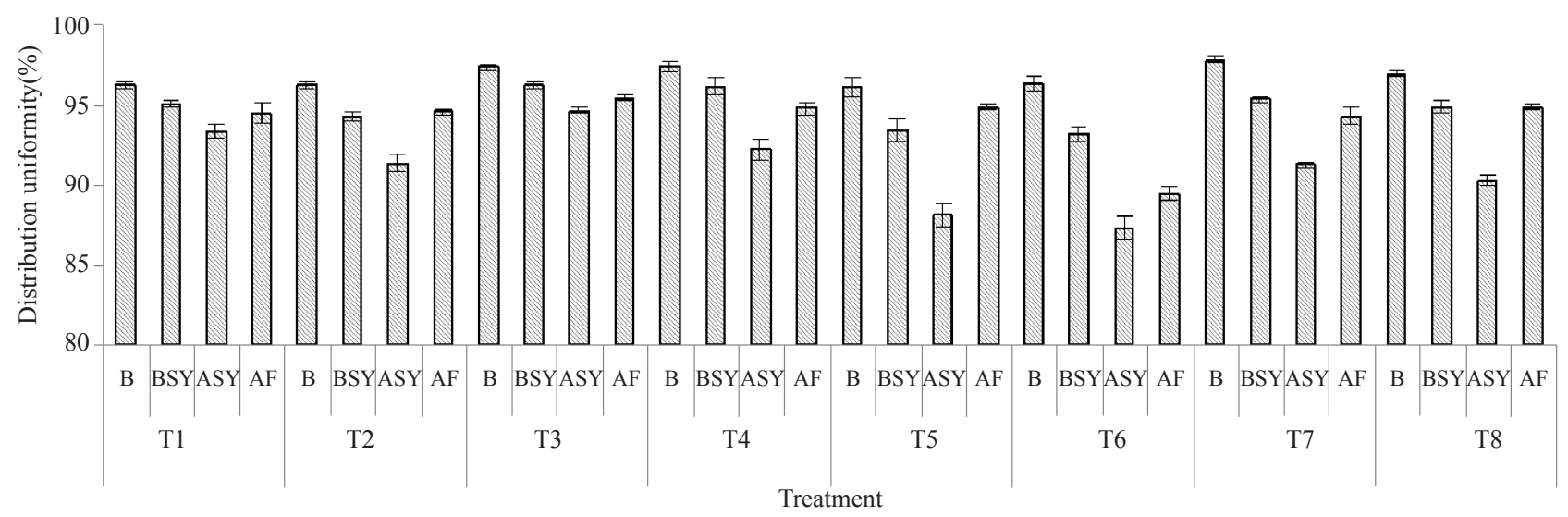

Figure 2. Distribution uniformity and standard deviation of the emitters discharge and their location under different treatments during the study period for performance evaluation of drip irrigation system. B-at the beginning of the first year of the experiment, BSY-at the beginning of the second year of the experiment, ASY-at the end of the second year of the experiment, and AF-after flushing

\subsubsection{Coefficient of variation of emitter discharge along with the location}

The coefficient of variation (CV) of dripper discharge is depicted in Figures $3 \mathrm{a}, 3 \mathrm{~b}$ and $3 \mathrm{c}$. There was no CV observed during the beginning of the experiment when a new drip system was installed (Figure 3a). After 1 year of the experiment, the maximum $\mathrm{CV}$ of $5.2 \%$ was found in inline drip lateral and the minimum was $1.7 \%$ in bioline drip lateral (Figure 3b). CV along the drip lateral was also recorded. A 3\% CV was found between the first and last emitter within the same bioline drip laterals using groundwater, while $10.1 \% \mathrm{CV}$ was observed with inline drip laterals using wastewater. A maximum of $13.75 \% \mathrm{CV}$ was observed in inline drip laterals with subsurface using wastewater. Subsurface emitters showed poor performance in both the years over surface placement with higher CV (Figure 3c). After flushing, the improvement in the flow rate variation was observed in all the treatments. This may be attributed due to the flushing of the lateral removed the accumulation of sediment, which helped in reducing the clogging of emitters, and consequently, the flow rate was improved in all the treatments (Figure 1a-c).

\subsubsection{Distribution uniformity (DU) and observation of the emitter}

The distribution uniformity of surface and subsurface placement of drip laterals using wastewater and groundwater is presented in Figure 2. At the beginning of the field experiment, the highest distribution uniformity was observed, whereas distribution uniformity decreased considerably onwards the completion of the experiment. Minimum distribution uniformity (87.3\%) was observed in inline drip laterals with subsurface placement using wastewater while maximum (97.39\%) in the surface placement of bioline drip lateral using groundwater. Overall, distribution uniformity was improved by $3 \%$ to $5 \%$ by flushing the inline drip lateral. The state of different emitters at the beginning (at the time of transplanting) and at end of the tests (after the second year of the experiment) are shown in Figure 4. The deposition was visible in both the drip emitters. Inline drip emitter had some more dirt at inlet point as compared to bioline drip emitter. At the end of the experiment, a solid deposit was observed in both types of the emitter (bioline and inline) using the wastewater. Similar results were also recorded by [15, 36, 39]. In the present study, a biological film and physical material were found in a very less quantity in the laterals and emitters dispersing wastewater. Among all treatments, bioline drip laterals showed a higher value of DU and the lowest value of CV. The distribution uniformity of a drip system increased by $5 \%$ by single flushing at the end of the experiment [40]. Flushing of bioline drip lateral could improve only $1 \%$ to $2 \%$ distribution uniformity. [25] found a similar result in the case of pressure compensating drip laterals using a sand-disc filtration system by flushing. Subsurface placement of emitters showed poor distribution uniformity over surface placement. At the end of the laterals, the flow rate variation was highest which indicated a greater number of dripper clogging occurred due to lower velocity at this point allow the particles to settle down $[9,41]$. 

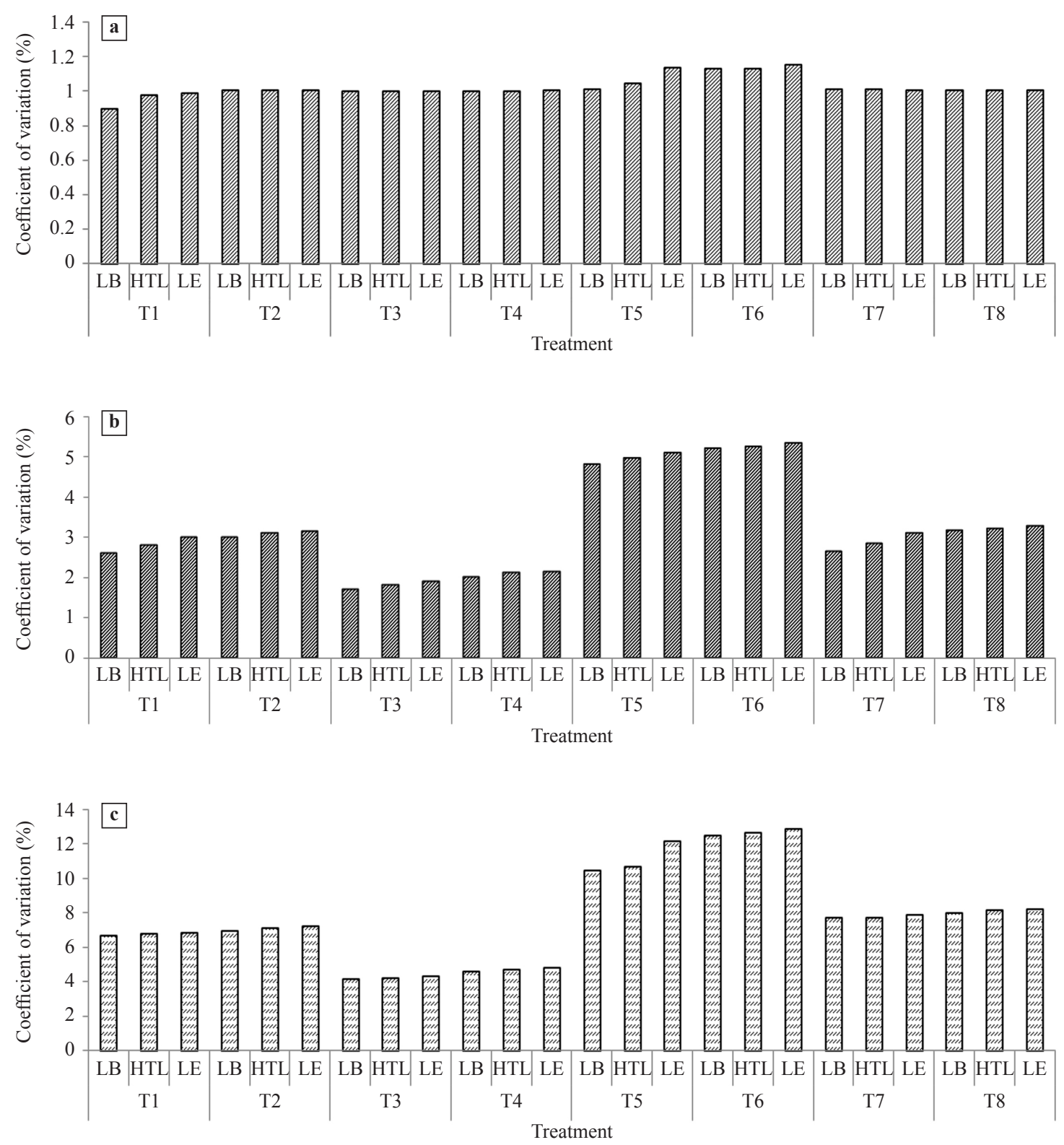

Figure 3. Coefficient of variation and standard deviation of the emitter's discharge and their location under different treatments during the study LB-emitter at the lateral beginning, HTL-emitter at half of the total length, and LE-emitter at the lateral end

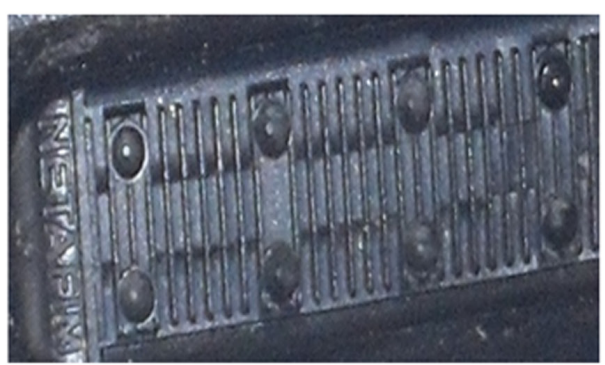

a

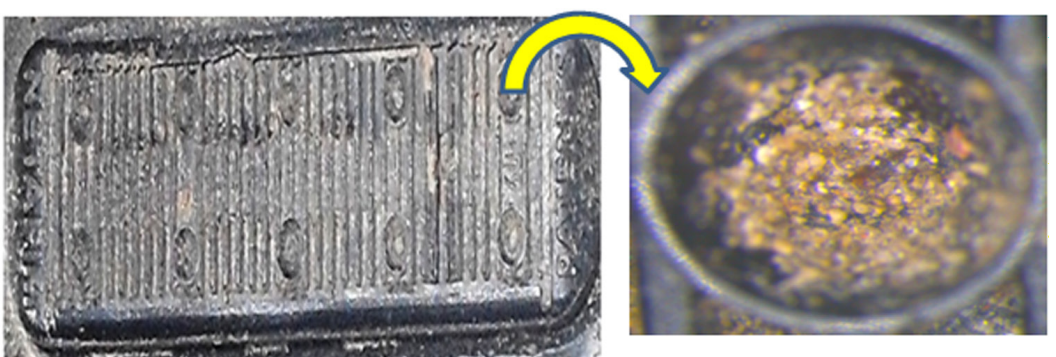

$\mathrm{b}$
1 


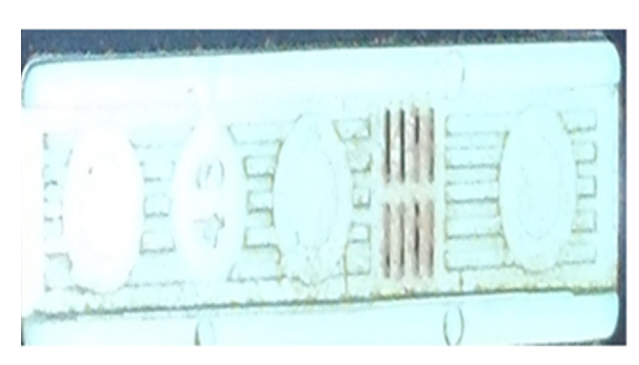

$\mathrm{c}$

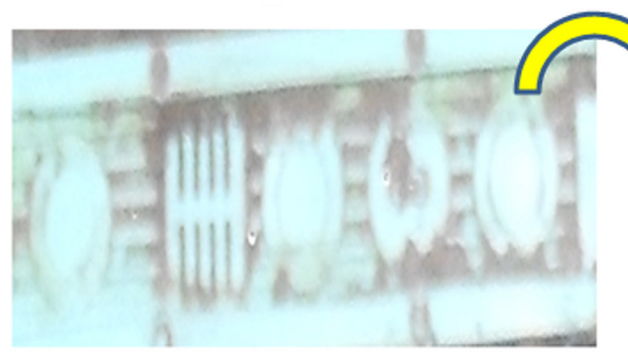

$\mathrm{d}$

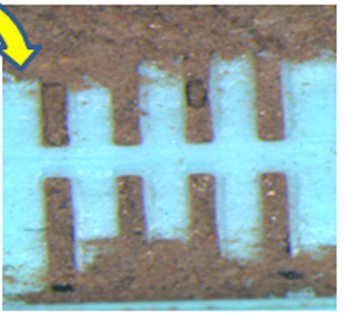

2

Figure 4. Internal view of bioline and inline emitters at different stages

a-bioline emitter at the time of transplanting (beginning of the experiment), b-bioline emitter at the harvesting stage (after the second year), c-inline emitter at the time of transplanting (beginning of the experiment), and d-inline emitter at the harvesting stage (after the second year). 1 and 2 are the microscopic view of bioline and inline emitters.

\section{Conclusions}

The present study aimed to assess the effects of type of emitters, depth of lateral placement, and water quality on clogging of the emitter and sand-disk filter. The major substances that participated in the clogging of emitter were EC, $\mathrm{pH}, \mathrm{HCO}_{3}$, Turbidity, $\mathrm{Ca}, \mathrm{Mg}$, total solid, E. coli, and total coliform. It was observed that these substances $\left(\mathrm{EC}, \mathrm{HCO}_{3}\right.$, Turbidity, Ca, total solid, E.coli, and total coliform) of wastewater were categorized with a medium risk of clogging except for $\mathrm{pH}$ and magnesium (low risk of clogging). Results showed that the clogging of pressure compensating as compared to non-pressure compensating dripper presented a moderate clogging hazard while the interaction of emitter type with flushing treatment showed minor clogging hazard. The best hydraulic performance revealed that the pressure compensating emitter in combination with surface placement and sand-disc filter would be the most appropriate strategy to cope with emitter clogging when using wastewater. This combination also resulted in reasonably good distribution uniformity with a greater emitter discharge exponent. Flushing was found to be an effective means to control emitter clogging and improve emitter discharge.

\section{Acknowledgment}

The authors wish to thank the National Committee on the Plasticulture Applications in Horticulture (NCOAH), Department of Agriculture and Corporation, Ministry of Agriculture (GoI), for providing the necessary facilities to conduct this research.

\section{Conflict of interest}

The authors declare that they have no conflict of interest.

\section{References}

[1] Singh D, Goyal VC. Planning of agricultural inputs in Ur watershed to maximize net benefit under limited resources. Indian Journal of Agricultural Sciences. 2018; 88(2): 326-332.

[2] Yadav D, Shivay YS, Singh YV, Sharma VK, Bhatia A. Water use and soil fertility under rice-wheat cropping system in response to green manuring and zinc nutrition. Communication in Soil Science and Plant Analysis. 2019; 50(22): 2836-2847.

[3] Taylor HD, Bastos X, Pearson HW, Mara DD. Drip irrigation with waste stabilization pond effects: solving the problem of emitter fouling. Water Science \& Technology. 2005; 31(12): 417-424.

[4] Singh D, Patel N, Gadedjisso-Tossou A, Patra S, Singh N, Singh PK. Incidence of Escherichia coli in vegetable 
crops and soil profile drip-irrigated with primarily treated municipal wastewater in a semi-arid peri-urban area. Agriculture. 2020a; 10(7): 291.

[5] Rai PK, Tripathi BD. Microbial contamination in vegetables due to irrigation with partially treated municipal wastewater in a tropical city. International Journal of Environmental Health Research. 2007; 17(5): 389-395.

[6] Singh D, Patel N, Patra S, Singh N. Growth and yield of cauliflower under surface and subsurface drip irrigation with primarily treated municipal wastewater in a semi-arid peri-urban area. Current Science. 2020b; 119(8): 1357.

[7] Tripathi VK, Rajput TBS, Patel N. Performance of different filter combinations with surface and subsurface drip irrigation systems for utilizing municipal wastewater. Irrigation Science. 2014; 32: 379-391.

[8] Tripathi VK, Rajput TBS, Patel N. Biometric properties and selected chemical concentration of cauliflower influenced by wastewater applied through surface and subsurface drip irrigation system. Journal of Cleaner Production. 2016; 139: 396-406.

[9] Singh D, Patel N, Patra S, Singh N, Roy T, Caucci S, et al. Efficacy of drip irrigation in controlling heavy metal accumulation in soil and crop using wastewater. Journal of Environmental Engineering and Science. 2021; 16(3): 109-121. Available from: https://doi.org/10.1680/jenes.20.00056.

[10] Duran-Ros M, Puig-Bargues J, Arbat G, Barragan J, Ramirez D, Cartagena F. Performance and backwashing efficiency of disc and screen filters in micro irrigation systems. Biosystems Engineering. 2009; 103: 35-42.

[11] Albaji M, Golabi M, Nasab SB, Zadeh FN. Investigation of surface, sprinkler and drip irrigation methods based on the parametric evaluation approach in Jaizan Plain. Journal of the Saudi Society of Agricultural Sciences. 2015; 14(1): 1-10.

[12] Yao C, Zhang L, Wu P, Liu Y, Cai Y, Zhou W. Clogging formation and an anti-clogging method in subsurface irrigation system with porous ceramic emitter. Agricultural Water Management. 2021; 250: 106770. Available from: https://doi.org/10.1016/j.agwat.2021.106770.

[13] Wu F, Fim Y, Li H, Guo Z, Li J, Li W. Clogging of emitter in subsurface drip irrigation system. Transactions of the CSAE. 2004; 20(1): 80-83.

[14] Song P, Li Y, Zhou B, Zhou C, Zhang Z, Li J. Controlling mechanism of chlorination on emitter bio-clogging for drip irrigation using reclaimed water. Agricultural Water Management. 2017; 184: 36-45.

[15] Zhang W, Niu W, Li G, Wang J, Wang Y, Dong A. Lateral inner environment changes and effects on emitter clogging risk for different irrigation times. Agricultural Water Management. 2020; 233: 106069. Available from: https://doi.org/10.1016/j.agwat.2020.106069.

[16] Capra A, Scicolone B. Recycling of poor quality urban wastewater by drip irrigation systems. Journal of Cleaner Production. 2007; 15: 1529-1534.

[17] Song P, Feng G, Brooks J, Zhou B, Zhou H, Zhao Z, et al. Environmental risk of chlorine-controlled clogging in drip irrigation system using reclaimed water: the perspective of soil health. Journal of Cleaner Production. 2019; 232: 1452-1464.

[18] Eroglu S, Sahin U, Tunc T, Sahin, F. Bacterial application increased the flow rate of $\mathrm{CaCO}_{3}$-clogged emitters of drip irrigation system. Journal of Environmental Management. 2012; 98: 37-42.

[19] Ma C, Xiao Y, Puig-Bargués J, Shukla MK, Tang X., Hou P, et al. Using phosphate fertilizer to reduce emitter clogging of drip fertigation systems with high salinity water. Journal of Environmental Management. 2020; 263: 110366. Available from: https://doi.org/10.1016/j.jenvman.2020.110366.

[20] Singh D, Patel N, Rajput TBS, Varghese C. Study of soil water dynamics under bioline and inline drip laterals using groundwater and wastewater. Journal of Soil and Water Conservation. 2013; 12(1): 55-58.

[21] Capra A, Scicolone B. Emitter and filter tests for wastewater reuse by drip irrigation. Agricultural Water Management. 2004; 68(2): 135-149.

[22] El-Berry AM, Bakeer GA, Al-Weshali AM. The effect of water quality and aperture size on clogging of emitters. Improved irrigation technologies and methods: Research, development and testing. Proceedings ICID International workshop, Montpellier, France; 2003. pp. 1-11.

[23] Dazhuang YAN, Zhihui B, Rowan M, Likun GU, Shumei R, Peiling Y. Biofilm structure and its influence on clogging in drip irrigation emitters distributing reclaimed wastewater. Journal of Environmental Sciences. 2009; 21(6): 834-841.

[24] Ramachandrula VR, Kasa RR. Non-destructive characterization of physical and chemical clogging in cylindrical drip emitters. Heliyon. 2020; 6(10): e05327.

[25] Puig-Bargue G, Arbat M, Elbana M, Duran-Ros J, Barragan F, Cartagena FR. Effect of flushing frequency on emitter clogging in micro-irrigation with effluents. Agricultural Water Management. 2010; 97: 883-891.

[26] Desai S, Hasan M, Sonawane A, Rajurkar GB, Singh D. Effect of different levels of drip irrigation and potassium fertilizer on fruit yield and quality of Kinnow (Citrus reticulata Blanco). International Agricultural Engineering 
Journal. 2014; 23(2): 50-56.

[27] Qingsong W, Gang L, Jie L, Yusheng S, Wenchu D, Shuhuai H. Evaluations of emitter clogging in drip irrigation by two-phase flow simulations and laboratory experiments. Computers and Electronics in Agriculture. 2008; 63(2): 294-303.

[28] Cararo DC, Botrel TA, Hills DJ, Leverenz HL. Analysis of clogging in drip emitters during wastewater irrigation. Applied Engineering in Agriculture. 2006; 22(2): 251-257.

[29] Liu Z, Xia Y, Li Y, Zhou B, Feng J, Han S, et al. Influence of operating pressure on emitter anti-clogging performance of drip irrigation system with high-sediment water. Agricultural Water Management. 2019; 213: 174184.

[30] De Kreij C, Van der Burg AMM, Runia WT. Drip irrigation emitter clogging in Dutch greenhouses as affected by methane and organic acids. Agricultural Water Management. 2003; 60(2): 73-85.

[31] Dehghanisanij H, Yamamoto T, Ould AB, Fujiyama HY, Miyamoto K. The effect of chlorine on emitter clogging induced by algae and protozoa and the performance of drip irrigation. Transactions of ASAE. 2005; 48(2): 519-527.

[32] Magwenzi O. Efficiency of subsurface drip irrigation in commercial sugarcane field in Swaziland. Proceedings of the South African Sugar Technologists Association; 2001. Available from: http://wastewaterw.sasa.org.za/sasex/ aboutlagronomy/aapdfs/magroundwaterenzi.pdf.

[33] Keller J, Karmeli D. Trickle irrigation design parameters. Transactions ASAE. 1974; 17(4): 678-684.

[34] Westcot DW, Ayers RS. Irrigation water quality criteria. Irrigation with reclaimed municipal wastewater: In: Pettygrove GS, Asano T. (eds.) Irrigation With Reclaimed Municipal Wastewater-A Guidance Manual. Lewis Publishers, Inc. Chelsea, MI; 1985. Available from: https://doi.org/10.1201/9781351073905-3.

[35] Urbano VR, Mendonc ATG, Bastos RG, Souza CF. Physical-chemical effects of irrigation with treated wastewater on Dusky Red Latosol soil. Ambiente and Água-An Interdisciplinary Journal of Applied Science. 2015; 10: 737747.

[36] Solé-Torres C, Puig-Bargués J, Duran-Ros M, Arbat G, Pujol J, de Cartagena FR. Effect of different sand filter underdrain designs on emitter clogging using reclaimed effluents. Agricultural Water Management. 2019; 223: 105683. Available from: https://doi.org/10.1016/j.agwat.2019.105683.

[37] Muhammad T, Zhou B, Liu Z, Chen X, Li Y. Effects of phosphorus fertigation on emitter clogging in drip irrigation system with saline water. Agricultural Water Management. 2021; 243: 106392. Available from: https://doi. org/10.1016/j.agwat.2020.106392.

[38] ASABE. Design and installation of micro-irrigation systems, EP405.1, ASABE standards, 50th edition. American Society of Agricultural and Biological Engineers, St. Joseph, Michigan; 2003.

[39] Han S, Li Y, Zhou B, Liu Z, Feng J, Xiao Y. An in-situ accelerated experimental testing method for drip irrigation emitter clogging with inferior water. Agricultural Water Management. 2019; 212: 136-154.

[40] Liu H, Huang G. Laboratory experiment on drip emitter clogging with fresh water and treated sewage effluent. Agricultural Water Management. 2009; 96: 745-756.

[41] Li JS, Li YF, Zhang H. Tomato yield and quality and emitter clogging as affected by chlorination schemes of drip irrigation systems applying sewage effluent. Journal of Integrative Agriculture. 2012; 11(10): 1744-1754. 